occasional contagiousness of leprosy. If, however, we make a clear distinction between skin.contagion and communication by the mouth, are they of any value? Is it not in the Dublin case quite likely that the brother who contracted the disease, as is supposed, from wearing his leprous brother's clothes, also exposed himself to risk by taking food which had been touched and contaminated? The two brothers lived together in a peasant's cabin and very probably used the same drinking vessels, knives, spoons, \&c. The possibility of skin contagion-which perhaps ought alone to be called "contagion"-is discredited by a thousand facts, whilst the reality of mouth-communication (i.e., by food) is, I think, doubted by none. To which then ought we to refer these very exceptional facts?

As regards the failure or otherwise of segregation measures, it is too large a subject for me to discuss in a letter. must be content to observe respecting the asserted increase in Madagascar that it may have been due to increased facilities for the transport of fish. I possess a good deal of information as regards that island but there is scarcely any place in the world from which I should less hopefully expect any trustworthy data as to the prevalence and causes of leprosy. It has been asserted respecting many other places that the disease increased when segregation was neglected but the fact is that it has often died out under absolute neglect of it and as often thriven in spite of its energetic enforcement. It is increasing now in Cape Colony, \&c., in spite of the enforcement of cruel laws and it is steadily dying out in Norway although the number of those segregated has been diminishing. In the latter country registration and good advice as to eating, \&c., would appear to be all that is needed. The leper is allowed to remain at home with his friends and the miseries of such places as Robben Island are unknown there. I am, Sirs, yours faithfully,

June 30th, 1906

JONATHAN HUTCHINSON.

\section{HYGIENIC MEASURES AGAINST SYPHILIS.}

To the Editors of THE LANOET.

SIRS,-In Dr. B. Leppington's criticism of Professor Metchnikoff's third lecture (on syphilis) it is possible to agree with him in his warnings as to the incompleteness of the experiment. Dr. Leppington, however, speaks of Professor Metchnikoff's "parrot's" cry " that hygiene must be paramount over morality" and then asks what Professor Metchnikoff means by morality? He answers, Professor Metchnikoff " evidently means that the combat with disease is to be unflinchingly carried on by means which involve a definite deterioration of public morality." Dr. Leppington then says "the supreme ally of the hygienist is a rising level of morality, which by diminishing the area of vice diminishes the difficulty attending the campaign against the consequences of vice," and finishes by saying "that every hygienist who casts contempt against virtue is adding to the momentum of forces against himself." The implication of all this is that Professor Metchnikoff is engaged in a work that will lead to a diminished public morality; that he regards virtue of little value, and thus in the end will defeat his own aspirations.

Professor Metchnikoff needs no one to defend him. but Dr. Leppington's own views may be examined. He alleges (without proof) that the disease he is dealing with springs largely out of moral weakness. Does it? I am prepared to deny this. What is morality? Is it not the habit or way of life which conduces to the well-being of society and "ultimately is a matter of organisation, of instinct rather than of ratiocination? A knowledge of moral precepts, whether culled from works on ethics or heard in sermons, never made people moral, and never will. It is the ever present forces of life, heredity surroundings, that determine conduct, and the only way of affecting conduct for the ketter is by modifying the influence on human nature of those forces that are persistent and inescapable."

It may be very flattering to those of us who have not contracted syphilis and who have not perhaps been where it could be acquired to regard ourselves as morally strong. But our every action is governer by inflexible laws. The man with strong desires, whose motives to gratify those desires are stronger than any other he possesses, will gratify them so long as there is an opportunity irrespective of the consequences. The man whose desires are not so strong, whose dread of the consequences is greater than any pleasure he would derive from gratifying them, will not do so, but it is beside the question to say the one is morally strong and the other morally weak. It is sheer wrong-headedness not to recognise the fact that we cannot end the desires of either sex and that all we can do where their gratitication leads to disease is to limit the baneful effects as much as possible.

The question now arises, Who people the places where syphilis can be contracted? Not men who are morally weak (whatever that means) but men whose sexual desires are strong. As for the women, let Dr. Leppington read the words that Mr. Upton Sinclair in "The Jungle" puts into the mouth of Marija. We have it also on the authority of Lady Jeune that women sell their bodies for bread. So long as our present social conditions continue crushing and condemning millions to starvation so long will there be bodies for sale. The true remedy is that which shall prevent poverty and the day of that remedy is coming, is nearing, is at hand. For the present, however, we are restricted to "regulation" or "abolition." If it can be shown that "abolition" diminishes the amount of syphilis we should all be abolitionists. If, however, it simply serves to scatter the disease far and wide on the innocent as well as the "guilty," surely we should all be "regulationists." But it may be argued that that is legalising vice. It may be so, but we have had to legalise drinking and other "vices." It is also said "inspection" demoralises, but it is sheer silliness to say that one who has to submit to the embraces of a dozen strangers every night is demoralised by the visit of a medical man once or twice a week. What, then, of the morality, or rather immorality, of those who, like Dr. Leppington, because regulation does not stamp syphilis out, are prepared to let each unfortunate act as a focus of disease in the district in which she lives, infecting and damning innocent women and children? Surely the unborn have the strongest claim upon us because of their innocence and helplessness. It is not necessary to despise those of our sisters who have to submit to inspection-the man who does so shows he bas much to learn. We can feel for them and the stronger we feel the harder we will work for the abolition of that competitive system which is flinging millions on the street. Till that day dawns when the evils we speak of will have righted themselves no one has a right to speak of men like Professor Metchnikoff as casting contempt against virtue. The immoral man is not Professor Metchnikoff but he who would so order things as not to lead to the highest well-being of society.

Liverpool, July 1st, 1906. I am, Sirs, yours faithfully,

\section{THE ALLEGED GROWTH OF INSANITY. To the Editors of THE LANCET.}

SIRS,-DD. D. Nicolson in an interesting and suggestive letter published in THE LANCET of June 9th quotes from the last annual report of the Commissioners in Lunacy a statistical statement with reference to the increase in the number of the insane under their surveillance in England and Wales between Jan. 1st, 1869, and Jan. 1st, 1904-namely, from 53,177 to 119,829 . The sentence containing this statement quoted by Dr. Nicolson is : " In spite of this large numerical increase, it will be found that when considered in relation to the growth of population the proportion of insane has not increased as much as the population." Your correspondent states with regard to this quotaion: "With this definite expression of opinion on the part of those who are in the best position to know $\mathrm{I}$ am cortent to leave this aspect of the question." I do not, of course, presume to judge what precise signification $\mathrm{Dr}$. Nicolson attaches to what he descrines as a "definite expression of opinion" by the Commissioners in Lunacy, but it seems more than probable that this, to me, meaning less statement of the Oommissioners might lead many to believe that the rate of increase of the insane under their control between 1869 and 1904 was not so great as the rate of increase of the population. What are the facts of the case as stated by the Commissioners? The numerical increase of the insane during these 35 years was $125 \cdot 3$ per cent. and the numerical increase of the population duing the same period was only 536 per cent. Thus the number of the insane in reased more than twice as rapidly as the populalation. If, howerer, the increase of population be taken into 